\title{
The impact of long-term ventilator-use on health-related quality of life and the mental health of children with neuromuscular diseases and their families: need for a revised perspective?
}

\author{
Jessika Johannsen ${ }^{1 *}$ (D) Lena Fuhrmann ${ }^{1}$, Benjamin Grolle², Lydia Morgenstern³ ${ }^{3}$ Silke Wiegand-Grefe ${ }^{3}$ and
} Jonas Denecke ${ }^{1}$

\begin{abstract}
Background: Life extension by medical interventions and health-related quality of life (HRQOL) are sometimes conflicting aspects of medical care. Long-term ventilation in children with neuromuscular disease is a wellestablished life-extending procedure and often at the center of this conflict. HRQOL and the mental health of affected children and their families become even more important in respect to emerging therapies in neuromuscular diseases with longer life-expectancy of treated patients and considerable costs of medical treatment.

Methods: We performed a questionnaire survey in a total of forty-three families of children with neuromuscular disease treated in the University Medical Center Hamburg-Eppendorf and the Children's Hospital Altona. We evaluated self- and proxy-reported HRQOL and mental health outcomes of affected children and their parents using validated and age-appropriate instruments.
\end{abstract}

Results: Compared to normative data, children with neuromuscular diseases and their families experienced a lower HRQOL and mental health. However, there was no additional negative influence on the overall HRQOL by ventilator use.

Conclusions: As ventilator use was not responsible for the reduction of HRQOL and mental health our data contributes an important aspect to the discussion about life-prolonging procedures, in particular mechanical ventilation, in severly disabled patients.

\footnotetext{
* Correspondence: j.johannsen@uke.de

'Department of Pediatrics, University Medical Center Hamburg-Eppendorf, Hamburg, Martinistr, 5220246 Hamburg, Germany

Full list of author information is available at the end of the article
}

C C The Author(s). 2020 Open Access This article is licensed under a Creative Commons Attribution 4.0 International License, which permits use, sharing, adaptation, distribution and reproduction in any medium or format, as long as you give appropriate credit to the original author(s) and the source, provide a link to the Creative Commons licence, and indicate if changes were made. The images or other third party material in this article are included in the article's Creative Commons licence, unless indicated otherwise in a credit line to the material. If material is not included in the article's Creative Commons licence and your intended use is not permitted by statutory regulation or exceeds the permitted use, you will need to obtain permission directly from the copyright holder. To view a copy of this licence, visit http://creativecommons.org/licenses/by/4.0/. The Creative Commons Public Domain Dedication waiver (http://creativecommons.org/publicdomain/zero/1.0/) applies to the data made available in this article, unless otherwise stated in a credit line to the data. 


\section{Background}

Neuromuscular disorders are mostly life-limiting diseases using mechanical ventilation at any stage as a tool of palliative care extending life expectancy of the patients [1-3]. In recent years a growing number of new therapies in the field of neuromuscular diseases have emerged modifying the disease's course and enhancing the life-expectancy of affected children [4-6]. In this context two aspects of mechanical ventilation in those patients become more important: 1 . Extending patient's life expectancy with the option that new therapeutics are available in the future and 2. Focusing on the quality of life considering that new therapies might extend life expectancy but still do not reverse the course of the disease to a significant extent. One example in this discussion is the initiation of mechanical ventilation in patients with spinal muscular atrophy type 1 in the face of recently approved disease-modifying treatments such as nusinersen and/or Onasemnogene abeparvovec [4-7]. In everyday clinical practice, healthcare economy as well as the knowledge of patients and health care professionals are additional factors in the decision for or against ventilation in patients with neuromuscular disorders at any stage of the disease. How health care professionals' and caregivers' assess a patients' quality of life is crucial for medical counseling. However, HRQOL of technology-dependent and/or physically disabled children were reported to be significantly underestimated by caregivers $[8,9]$.

The care for a technology-dependent child leads to a significant burden on the caregivers and long-term dependence on medical equipment, which creates a considerable impediment of social life for the affected child and their families [10-13]. Moreover, an increased risk of externalizing and internalizing behavioural disorders, as well as developmental disorders and mental comorbidities were found in a longitudinal data analysis in families with technology-dependent children [14]. Additionally, parents of chronically ill children exhibit mental health problems and comorbidities due to the condition of their child, mostly in the spectrum of depression and anxiety disorders. The percentage of mothers with clinically significant anxiety and depression lies above 30 and $23 \%$ respectively [15]. Thus, the application of life-extending procedures, in particular ventilator use, must be embedded in the medical but also in the psychosocial context.

Considering this, the comparison of quality of life and mental health of non-ventilated and ventilated children with neuromuscular disease and their parents could be essential to the decision-making process of applying lifeextending procedures. The purpose of our study was to investigate health-related quality of life and mental health outcomes of affected children and their families enclosing the aspect of ventilation. In total, 43 families of children with neuromuscular disease treated in the University medical center Hamburg-Eppendorf and the Children's Hospital Altona were evaluated with standardized questionnaires and compared to a cohort of healthy children and children with other chronic diseases, respectively. In view of previous reports on health-related quality of life in ventilated patients [10, $12,14,16]$ we propose that long-term ventilation is one factor that impairs quality of life of affected children and their families due to an increase in disease burden.

\section{Methods \\ Participants}

Children and their parents were recruited during regularly scheduled clinic visits at the Department of Pediatrics, section neuropediatrics of the University Medical Center Hamburg-Eppendorf and the Pediatric Pulmonary Department of the Children's Hospital Altona, Hamburg. The following 2 patient groups were included: (1) children unter the age of 21 years with neuromuscular disease with invasive and/or non-invasive ventilation, (2) children under the age of 21 years with neuromuscular disease without invasive and/or noninvasive ventilation.

Children and their parents with limited germanlanguage comprehension or those who were unable to give informed consent were excluded. Families with children with cognitive impairment and/or severe additional diseases except the neuromuscular disease (for example epilepsy) were also excluded.

The following demographic information was collected by self-reported questionnaires and electronic health records: age of children and parents, gender of children, occupational status of parents, highest level of education of parents, family income, type of neuromuscular disorder, type and duration of mechanical ventilation.

Written, informed consent from the parents or guardians and assent from children who were able to read and understand the questionnaires were obtained before enrollment. Questionnaires were delivered to the families during the clinic visit or sent to the families' home and were completed at home. The study was approved by the local ethics committee (PV4361).

\section{Measurement instruments}

The primary study outcome was the mental health and health-related quality of life (HRQOL) of children and their parents. Mothers and fathers were interviewed separately.

In children, HRQOL was measured by the DISABKIDS-37 and the KIDSCREEN-27 questionnaires. The DISABKIDS37 was developed as part of a set of instruments to assess self-reported HRQOL in European children aged 8 to 16 
years with chronic health conditions and consists, in its long version (DCGM-37), of 37 likert-scaled items divided into the following scales: Independence, Emotion, Social inclusion, Social exclusion, Physical Limitation, and Treatment. In addition, this instrument provides a total score which represents an overall assessment of HRQOL. We used the questionnaire in the selfreported (child version) and the proxy version in german language [17]. The DCGM-37 showed acceptable to good internal consistencies $(\alpha=.70$ to .87$)$ and good to excellent test-retest reliabilities (ICC $=.71$ to .83) in a sample of children and adolescents with chronic health conditions [18] as well as acceptable internal consistencies in a pediatric sample undergoing cancer treatment, reflected by Cronbach's alpha above .70 on all HRQOL subcategories [19].

In contrast, the KIDSCREEN questionnaire was developed to evaluate HRQOL of healthy children aged 8 to 18 years. The KIDSCREEN-27 short version covers five dimensions of HRQOL: Physical Well-Being, Psychological Well-Being, Autonomy \& Parents, Peers \& Social Support and School Environment. Again, we used the self-reported and the proxy version in german translation [20].

The children's mental health was evaluated using the Strength and Difficulties questionnaire (SDQ, german translation). The SDQ is a behavioural screening questionnaire inquiring about 25 attributes and is available in the self-reported version for 11- to 16-year olds and the proxy version for parents with children between 4 and 16 years. The 25 items are divided between five scales of five items each, generating scores for Conduct Problems, Inattention/Hyperactivity, Emotional Symptoms, Peer Problems, and Prosocial Behavior. All scales except for the last are summed up to generate a Total Difficulties score [21]. Normative data of the German Health Interview and Exanimation Survey for children and adolescents (KiGGS) of the Robert Koch Institute were used for comparison [22].

The parental HRQOL was measured by the Ulmer Lebensqualitätsinventar für Eltern chronisch erkrankter Kinder (ULQIE). The ULQIE consists of 29 likert-scaled items containing five primary scales which cover five dimensions and a total score. The five primary scales are physical and daily functioning, satisfaction with the situation in the family, emotional distress, self-development, and well-being. Answers are given with regard to the preceding seven days on five-point rating scales ranging from 0 to 4 ('never' to 'always'). Higher scores indicate better quality of life. The test was developed for measuring parental quality of life in family-centered intervention programs and was validated in a group of parents with children suffering from oncologic disease, diabetes mellitus and epilepsy [23].
Mental health of parents was determined by the Brief Symptom Inventory (BSI). It evaluates psychological distress using a 53-item self-reported scale covering nine symptom dimensions: Somatization, Obsession-Compulsion, Interpersonal Sensitivity, Depression, Anxiety, Hostility, Phobic anxiety, Paranoid ideation and Psychoticism. For analyses, the three global indices of distress Global Severity Index (GSI), Positive Symptom Distress Index (PSDI), and Positive Symptom Total (PST) are calculated. The global indices measure current or past level of symptomatology, intensity of symptoms, and number of reported symptoms, respectively $[24,25]$.

\section{Statistical analysis}

The software IBM SSPS Statistics, version 22 was used to conduct all analyses. Missing values were filled up with the multiple imputation using the Markov Chain Monte Carlo (MCM) method. All analyses were performed for three different groups, consisting of, all families, $(n=43)$, families with ventilated patients $(n=18)$ and families with non-ventilated patients $(n=25)$ as well as separately for children (self-assessment and assessment by proxy) and their parents. For each variable, the violations of test assumptions, such as normality and homogeneity of variance were checked. T-Test for independent samples was used for comparison of averages between groups. The significance level was set at 0.05 .

\section{Results}

\section{Participants}

Out of seventy-seven contacted families forty-three families returned the questionnaires. Eighteen (41.9\%) families with ventilated children and 25 (48.1\%) families with non-ventilated children. Demographic data, type of neuromuscular disease and ventilation status of the patients are shown in Table 1 . Social standing of the families was comparable between groups. Ventilation treatment was initiated at the mean age of 4.42 years (SD: 5.44). In the ventilated group on average, children were ventilated for $13.21 \mathrm{~h}$ daily (SD: 6.53) and 4 of 18 (22.2\%) children needed ventilation $24 \mathrm{~h}$ a day. Five (27.8\%) children were ventilated since birth. In 13 (72.2\%) children, ventilation had to be started because of disease progression at the mean age of 4.4 years (SD: 5.44). Six (33.3\%) children were invasively ventilated via tracheostoma and 11 (61.1\%) children were on noninvasive ventilation. In one child, information about the ventilation type was missing.

Forty-two $(97.67 \%)$ mothers $\left(m_{t}\right)$ completed the questionnaire regarding parents' HRQOL and mental health compared to twenty-three $(53.49 \%)$ fathers $\left(f_{t}\right)$. All mothers of ventilated children $\left(\mathrm{m}_{\mathrm{v}}, n=18\right)$ and $24(96 \%)$ mothers of non-ventilated children $\left(\mathrm{m}_{\mathrm{nv}}\right)$ answered the 
Table 1 Demographic characteristics, type of neuromuscular disease, ventilation status and response rates of patients

\begin{tabular}{|c|c|c|c|}
\hline & \multicolumn{3}{|l|}{ children } \\
\hline & total & ventilated & non-ventilated \\
\hline Number of individuals & 43 & 18 & 25 \\
\hline Mean age in years (range) & $10.58(1-21)$ & $12.44(1-21)$ & $9.24(2-17)$ \\
\hline \multicolumn{4}{|l|}{ Ventilator-use, n (\%) } \\
\hline Full time use & & $4(22.2)$ & \\
\hline nocturnal use & & $8(44.4)$ & \\
\hline nocturnal and intermittent daily use & & $3(16.7)$ & \\
\hline intermittent as required & & $2(11.1)$ & \\
\hline missing data & & $1(5.6)$ & \\
\hline \multicolumn{4}{|l|}{ Type of ventilation technology, n (\%) } \\
\hline non-invasive & & $11(61.1)$ & \\
\hline invasive & & $6(33.3)$ & \\
\hline missing data & & $1(5.6)$ & \\
\hline muscular dystrophy Duchenne, n (\%) & $19(44.2)$ & $2(11.1)$ & $17(68)$ \\
\hline other muscular dystrophy, n (\%) & $8(18.6)$ & $1(5.6)$ & $7(28)$ \\
\hline spinal muscular atrophy, n (\%) & $6(13.9)$ & $6(33.3)$ & $0(0)$ \\
\hline congenital myopathy, n (\%) & $10(23.3)$ & $9(50)$ & $1(4)$ \\
\hline \multicolumn{4}{|l|}{ Completing the questionnaire (HRQOL), $n$} \\
\hline KIDSCREEN proxy version & 18 & 6 & 12 \\
\hline KIDSCREEN self-reported & 21 & 11 & 10 \\
\hline KIDSCREEN missing data & 4 & 1 & 3 \\
\hline DISABKIDS proxy version & 18 & 6 & 12 \\
\hline DISABKIDS self-reported & 21 & 11 & 10 \\
\hline DISABKIDS missing data & 4 & 1 & 3 \\
\hline \multicolumn{4}{|c|}{ Completing the questionnaire (mental health), $n$} \\
\hline SDQ proxy version & 18 & 6 & 12 \\
\hline SDQ self-reported & 21 & 11 & 10 \\
\hline SDQ missing data & 4 & 1 & 3 \\
\hline
\end{tabular}

questionnaires. The response rate was lower in fathers with $7(38.9 \%)$ fathers of ventilated children $\left(f_{v}\right)$ and 16 $(64 \%)$ fathers of non-ventilated children $\left(f_{\text {nv }}\right)$ completing the questionnaires. For the proxy measures, questionnaires were completed in $77,8 \%$ by the mothers, in 11 , $1 \%$ by the father and in $11,1 \%$ data showing which parent answered the questionnaire were missing. Response rates of patients are summarised in Table 1.

\section{HRQOL of affected children}

Measured by the KIDSCREEN-27, children with neuromuscular diseases ( $\operatorname{child}_{t}, n=21$ ) reported lower scores in Physical $(\mathrm{M}=39.1, \mathrm{SD}=6.22 ; p=.000)$ and Psychological Well-Being $(\mathrm{M}=37.05, \mathrm{SD}=3.24 ; \mathrm{p}=.000)$ than in the norm group of healthy children $(M=50, S D=10)$. In children with neuromuscular diseases, scores in $\mathrm{Au}$ tonomy \& Parents $(\mathrm{M}=58.76, \mathrm{SD}=10.28 ; p=.001)$ and in School Environment $(\mathrm{M}=53.74, \mathrm{SD}=7.88 ; p=.042)$ were higher than in healthy children. Similar results with lower scores of Physical and Psychological Well-Being and a higher score in Autonomy \& Parents were found in both sub-groups of ventilated (child,$n=11$, Physical Well-Being $(\mathrm{M}=39.15, \mathrm{SD}=7.52 ; p=.001)$, Psychological Well-Being $(\mathrm{M}=36.76, \mathrm{SD}=3.14 ; p=.000)$, Autonomy \& Parents $(\mathrm{M}=60.8, \mathrm{SD}=11.73 ; p=.012))$ and non-ventilated children (child ${ }_{n v}, n=10$, Physical WellBeing $(\mathrm{M}=39.05, \mathrm{SD}=4.81 ; \mathrm{p}=.000)$, Psychological Well-Being $(\mathrm{M}=37.37, \mathrm{SD}=3.5 ; \mathrm{p}=.000)$, Autonomy \& Parents $(\mathrm{M}=56.52, \mathrm{SD}=8.46 ; p=.038))$ compared to healthy children (Fig. 1a).

Consistently, parents of all children with neuromuscular diseases ( proxy $_{\mathrm{t}}, n=18$ ) reported lower scores in Physical $(\mathrm{M}=39.97, \mathrm{SD}=8.09 ; p=.000)$ and Psychological Well-being $(\mathrm{M}=32.63, \mathrm{SD}=3.75 ; p=.000)$ of their children compared to healthy children (Physical Well-being $(\mathrm{M}=49.98, \mathrm{SD}=10.01)$, Psychological Well- 


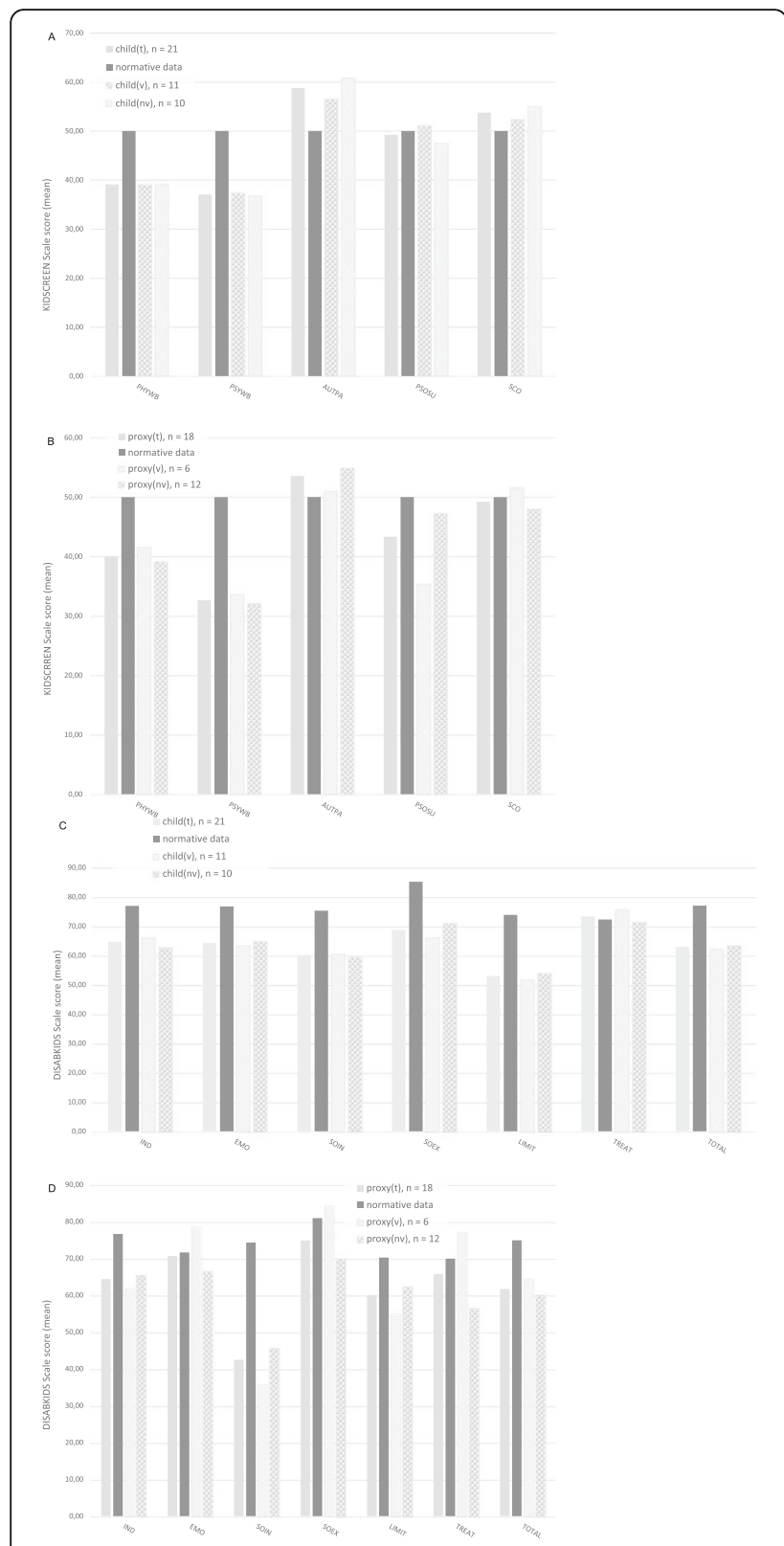

Fig. 1 Health-related quality of life reported by the children (self-reported) and by proxy (parents) respectively, measured with the German version of the KIDSCREEN-27 and the DISABKIDS-37. a self-reported HRQOL, measured by the KIDSCREEN-27; all children (child,$n=21$ ), ventilated children (child $d_{v} n=11$ ), non-ventilated children (child ${ }_{n v}, n=10$ ); $\mathbf{b} \mathrm{HRQOL}$ of the children reported by their parents, measured by the KIDSCREEN-27: all children ( $\operatorname{proxy}_{t}, n=18$ ), ventilated children ( $\operatorname{proxy}_{\mathrm{v}}, n=6$ ), nonventilated children ( $\operatorname{proxy}_{n v}, n=12$ ); c self-reported HRQOL, measured by the DISABKIDS-37; all children (child $d_{t}, n=21$ ), ventilated children (child $d_{v}$ $\mathrm{n}=11$ ), non-ventilated children (child ${ }_{n v}, n=10$ ); $\mathbf{d} H R Q O L$ of children reported by their parents, measured by the DISABKIDS-37; all children ( proxy $_{t}, n=18$ ), ventilated children (proxy $y_{v} n=6$ ), non-ventilated children (proxy $y_{n v} n=12$ ). Abbreviations: KIDSCREEN-27: PHMWB, Physical Well-Being; PSYWB, Psychological Well-Being; AUTPA, Autonomy and Parents; PSOSU, Peers and Social Support; SCO, School Environment. DISABKIDS-37: IND, Independence; EMO, Emotion; SOIN, Social Inclusion; SOEX, Social Exclusion; LIMIT, Limitation, TREAT, Treatment; TOTAL total quality of life being $(M=49.99, S D=10))$. In sub-groups, lower scores of Psychological Well-being $(\mathrm{M}=33.62, \quad \mathrm{SD}=3.3$; $p=.000)$ in ventilated children ( $\left.\operatorname{proxy}_{\mathrm{v}}, n=6\right)$ and lower scores of Physical Well-being $(\mathrm{M}=39.16, \mathrm{SD}=6.13$; $\mathrm{p}=.000)$ and Psychological Well-being $(\mathrm{M}=32.13, \mathrm{SD}=$ 4.0; $\mathrm{p}=.000)$ in non-ventilated children $\left(\operatorname{proxy}_{\mathrm{nv}}, n=12\right)$ compared to norm data of healthy children (Physical Well-being $(\mathrm{M}=49.98, \mathrm{SD}=10.01)$, Psychological Wellbeing $(M=49.99, S D=10)$ were confirmed by the parents. Additionally, parents stated a lower score in Peers \& Social Support $(\mathrm{M}=43.33, \mathrm{SD}=11.60)(p=.026)$ of their children with neuromuscular diseases than parents of healthy children $(M=50, S D=10)$. This was even lower $(p=.035)$ in the sub-group of ventilated children $(\mathrm{M}=35.38, \mathrm{SD}=15.33)$ compared to non-ventilated children $(M=47.30, S D=7.02)$ (Fig. 1b).

Self-reported quality of life measured by the DISABKIDS-37 was significantly lower in total (Global score $\mathrm{M}=62.94, \mathrm{SD}=17.39 ; p=.001$ ) and in all subscales except Treatment in children with neuromuscular disease ( child $\left._{\mathrm{t}}, n=21\right)$ (Independence $(\mathrm{M}=64.68, \mathrm{SD}=$ $19.21 ; p=.009), \quad$ Emotion $\quad(\mathrm{M}=64.29, \quad \mathrm{SD}=20.86$; $p=.013)$, Social inclusion $\quad(\mathrm{M}=60.12, \quad \mathrm{SD}=20.69$; $p=.003), \quad$ Social exclusion $\quad(\mathrm{M}=68.85, \quad \mathrm{SD}=20.57$; $\mathrm{p}=.001)$, Physical Limitation $(\mathrm{M}=52.98, \quad \mathrm{SD}=17.93$; $p=.000)$ ) compared to norm data of children with other chronic diseases (Global score $(\mathrm{M}=76.99, \mathrm{SD}=14.22)$, Independence $(M=76.9, S D=18.34)$, Emotion $(M=$ 76.72, $\mathrm{SD}=20.56)$, Social inclusion $(\mathrm{M}=75.25, \mathrm{SD}=$ 17.81), Social exclusion $(M=85.1, S D=15.56)$, Physical Limitation $(M=73.85, S D=18.23))$. In comparison with chronically ill children of the norm data group, in ventilated children (child,$n=11)$ overall score $(M=62.32$, $\mathrm{SD}=19.04 ; p=.029)$ and scores in Social inclusion $(\mathrm{M}=$ $60.61, \mathrm{SD}=20.19 ; p=.037)$, Social exclusion $(\mathrm{M}=66.29$, $\mathrm{SD}=19.23 ; p=.009)$ and Physical Limitation $(\mathrm{M}=51.98$, $\mathrm{SD}=18.2 ; p=.003)$ were lower, similar results were found in non-ventilated children (child ${ }_{\text {nv }}, n=10$ ) in overall score $(\mathrm{M}=63.63, \mathrm{SD}=16.39 ; p=.030)$ and in scores of Emotion $(\mathrm{M}=65.00, \mathrm{SD}=15.32 ; p=.039)$ and Limitation $(\mathrm{M}=54.17, \mathrm{SD}=18.35 ; p=.008)$. Scores were not significantly different between ventilated and nonventilated children (Fig. 1c).

According to their parents, children with neuromuscular disease ( $\operatorname{proxy}_{\mathrm{t}}, n=18$ ) are significantly impaired in total $(\mathrm{M}=61.66, \mathrm{SD}=11.76 ; p=.000)$ and in the scales Independence $(\mathrm{M}=64.35, \mathrm{SD}=14.52 ; p=.002)$, Social Inclusion $(\mathrm{M}=42.44, \mathrm{SD}=14.2 ; \mathrm{p}=.000)$ and Physical Limitation $(\mathrm{M}=59.95, \mathrm{SD}=15.99 ; p=.015)$ compared to children with other chronic diseases of the norm data group (total $(\mathrm{M}=74.90, \mathrm{SD}=14.55)$, Independence $(\mathrm{M}=76.7, \mathrm{SD}=17.25)$, Social Inclusion $(\mathrm{M}=74.28, \mathrm{SD}=$ 17.65), Physical Limitation $(M=70.19, \quad S D=18.32))$. Lower scores of Social inclusion $(\mathrm{M}=35.67, \mathrm{SD}=16.42$; 
$p=.002)$ and Physical limitation $(\mathrm{M}=54.86, \mathrm{SD}=11$; $p=.019)$ were also reported by the parents in the subgroup of ventilated children ${\left.\text { ( } \text { roxy }_{\mathrm{v}}, n=6\right)}$ compared to the norm group of children with chronic diseases. In non-ventilated children $\left(\operatorname{proxy}_{\mathrm{nv}}, n=12\right.$ ) not only the overall score $(\mathrm{M}=60.3, \mathrm{SD}=11.97 ; p=.001)$ and the scores in Independence $(\mathrm{M}=65.63, \mathrm{SD}=13.89 ; \mathrm{p}=.019)$ and Social inclusion $(\mathrm{M}=45.83, \mathrm{SD}=12.31 ; p=.000)$ were lower than in children with chronic disease but also the score in Treatment $(M=56.67, S D=21.37$ vs. $\mathrm{M}=69.9, \mathrm{SD}=22.15 ; \mathrm{p}=.001)$. There was no significant difference between non-ventilated and ventilated children (Fig. 1d).

\section{Mental health of affected children}

Using the SDQ, self-reported mental health scores in all children with neuromuscular disease $\left(\right.$ child $_{t}, n=$ 21) and in the sub-group of non-ventilated children (child $_{\text {nv }}, n=10$ ) were similar to healthy children. Though, ventilated children $\left(\operatorname{child}_{\mathrm{v}}, n=11\right)$ reported lower scores measuring conduct problems $(\mathrm{M}=1.27$, $\mathrm{SD}=0.79 ; p=.024)$ than healthy children $(\mathrm{M}=1.4$, $\mathrm{SD}=0.79)$ and significantly higher scores scaling prosocial behaviour $(\mathrm{M}=8.91, \mathrm{SD}=1.22 ; p=.008)$ compared to healthy children $(\mathrm{M}=7.70, \quad \mathrm{SD}=1.70$; $\mathrm{p}=.008)$ and to non-ventilated children $(\mathrm{M}=7.40$, $\mathrm{SD}=1.71 ; p=.03) \quad(($ Fig. $2 \mathrm{a})$.

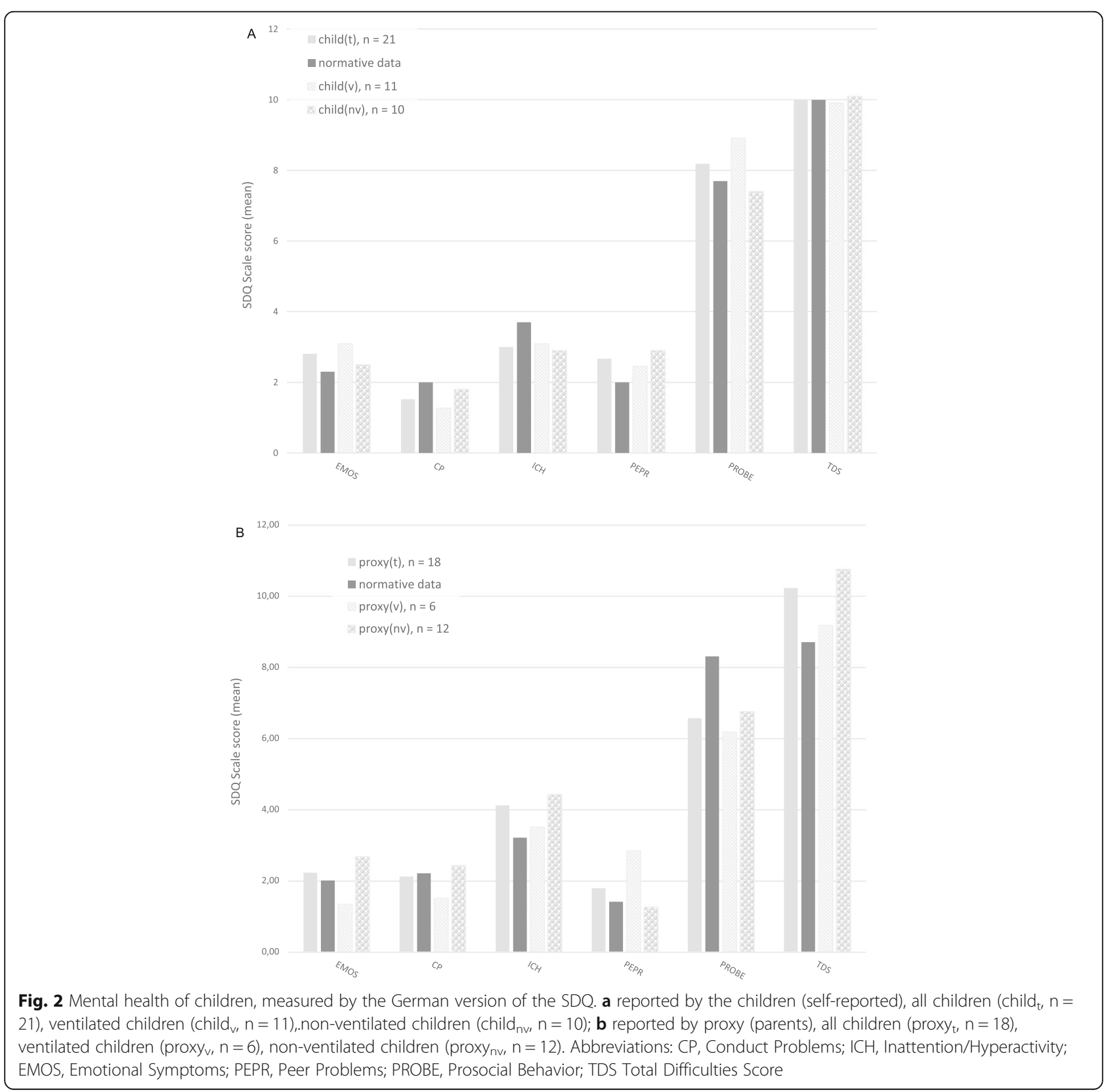


Parents estimated the prosocial behaviour of their chil-

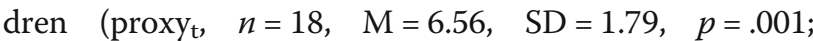
$\operatorname{proxy}_{\mathrm{v}}, n=6, \mathrm{M}=6.1, \mathrm{SD}=1.49, p=.015 ; \operatorname{proxy}_{\mathrm{nv}}, n=$ $12, \mathrm{M}=6.75, \mathrm{SD}=1.96, \quad p=.019)$ to be significantly lower compared to the norm group of children $(M=8.3$, $\mathrm{SD}=0.02$ ). More problems with peers were reported by parents in their ventilated children $(\mathrm{M}=2.83, \mathrm{SD}=1.47)$ than in non-ventilated children $(\mathrm{M}=1.25, \mathrm{SD}=1.36)$ $(p=.037)$ (Fig. 2b).

\section{HRQOL of mothers and fathers}

In the group of all mothers $\left(\mathrm{m}_{\mathrm{t}}, n=42\right)$ irrespective if the child is ventilated $\left(\mathrm{m}_{\mathrm{v}}, n=18\right)$ or not $\left(\mathrm{m}_{\mathrm{nv}}, n=24\right)$ no differences were found in any of the 5 dimensions of the ULQIE compared to parents with chronically ill children of the norm group. Mothers with ventilated children and mothers with non-ventilated children showed no differences in HRQOL as well (Fig. 3a).

In the group of fathers $\left(f_{t}, n=23\right)$, higher scores were reached in physical and daily functioning $(M=2.81$, $\mathrm{SD}=0.74 ; p=.026)$ and well-being $(\mathrm{M}=3.07, \mathrm{SD}=0.67$; $p=.011)$ compared to normative data of parents with chronically ill children (physical and daily functioning $(\mathrm{M}=2.44, \mathrm{SD}=0.72)$, well-being $(\mathrm{M}=2.68, \mathrm{SD}=0.69))$. Compared to parents with chronically ill children, no differences in HRQOL were found in fathers with ventilated children $\left(\mathrm{f}_{\mathrm{v}}, n=7\right)$, but fathers with non-ventilated children $\left(f_{n v}, n=16\right)$ showed higher scores in physical and daily functioning $(\mathrm{M}=2.87, \mathrm{SD}=0.6 ; p=.012)$, wellbeing $(\mathrm{M}=3.16, \mathrm{SD}=0.5 ; p=.002)$ and in the total scale $(\mathrm{M}=2.8, \mathrm{SD}=0.41$ vs. $\mathrm{M}=2.56, \mathrm{SD}=0.53 ; p=.03)$. Selfdevelopment was significantly higher scaled in the group of fathers with non-ventilated children $(\mathrm{M}=2.09, \mathrm{SD}=$ $0.55)$ compared to fathers with ventilated children $(\mathrm{M}=$ $1.46, \mathrm{SD}=0.71)(p=.032)($ Fig. $3 \mathrm{~b})$.

\section{Mental health of mothers and fathers}

In comparison with normative data, mothers in our group $\left(\mathrm{m}_{\mathrm{t}}, n=42\right)$ showed lower scores in the scale Psychoticism $(\mathrm{M}=0.12, \mathrm{SD}=0.21$ vs. $\mathrm{M}=0.19, \mathrm{SD}=0.27$; $p=.049)$. Moreover, mothers with ventilated children $\left(\mathrm{m}_{\mathrm{v}}, n=18\right)$ expressed lower scores in the scales Interpersonal Sensitivity $(\mathrm{M}=0.32, \mathrm{SD}=0.33 ; p=0.42)$ and Psychoticism ( $M=0.09, M=0.02 ; \mathrm{p}=.04)$ and mothers with non-ventilated children $\left(\mathrm{m}_{\mathrm{nv}}, n=24\right)$ had lower scores in the dimension Phobic anxiety $(\mathrm{M}=0.07, \mathrm{SD}=$ 0.13 ; $p=.002$ ) compared to normative data (Interpersonal sensitivity $\mathrm{M}=0.49, \mathrm{SD}=0.45$; Psychoticism $\mathrm{M}=$ $0.19, \quad \mathrm{SD}=0.27$; Phobic anxiety $\mathrm{M}=0.16, \quad \mathrm{SD}=0.25$ ) (Fig. 4a).

Fathers $\left(f_{t}, n=23\right)$ of children with neuromuscular disease reported lower mental stress with lower scores in PSDI $(M=0.98, S D=0.44 ; p=.043)$, Interpersonal Sensitivity $(\mathrm{M}=0.17, \mathrm{SD}=0.27 ; p=.004)$, Anxiety $(\mathrm{M}=0.13$,
$\mathrm{SD}=0.15 ; \quad p=.000), \quad$ Hostility $\quad(\mathrm{M}=0.20, \quad \mathrm{SD}=0.18 ;$ $p=.026)$, Paranoid Ideation $(\mathrm{M}=0.19, \quad \mathrm{SD}=0.22$; $p=.007$ ), compared to normative data (PSDI $M=1.18$, $\mathrm{SD}=0.33$, Interpersonal Sensitivity $\mathrm{M}=0.35, \mathrm{SD}=0.40$, Anxiety $\mathrm{M}=0.29, \mathrm{SD}=0.31$, Hostility $\mathrm{M}=0.29, \mathrm{SD}=$ 0.35 , Paranoid Ideation $\mathrm{M}=0.33, \mathrm{SD}=0.40$ ). In the subgroups, fathers with non-ventilated children $\left(\mathrm{f}_{\mathrm{nv}}, n=16\right)$ revealed lower mental stress in almost all dimension and in the global indices GSI and PST compared to normative data (Obsession Compulsion $\mathrm{M}=0.26, \mathrm{SD}=0.23$ vs. $\mathrm{M}=0.50, \mathrm{SD}=0.46 ; p=.001 ;$ Interpersonal Sensitivity $\mathrm{M}=0.13, \mathrm{SD}=0.18$ vs. $\mathrm{M}=0.35, \mathrm{SD}=0.40 ; p=.000 ;$ Anxiety $\mathrm{M}=0.11, \mathrm{SD}=0.12$ vs. $\mathrm{M}=0.29, \quad \mathrm{SD}=0.31$; $\mathrm{p}=.000$; Hostility $\mathrm{M}=0.20, \mathrm{SD}=0.15$ vs. $\mathrm{M}=0.29, \mathrm{SD}=$ $0.35 ; p=.026$; Phobic anxiety $\mathrm{M}=0.05, \mathrm{SD}=0.12$ vs. $\mathrm{M}=0.14, \mathrm{SD}=0.23 ; p=.007$; Paranoid Ideation $\mathrm{M}=$ $0.16, \mathrm{SD}=0.21$ vs. $\mathrm{M}=0.33, \mathrm{SD}=0.40 ; p=.006$; Psychoticism $\mathrm{M}=0.06, \quad \mathrm{SD}=0.12 \quad$ vs. $\mathrm{M}=0.19, \quad \mathrm{SD}=0.28$; $\mathrm{p}=.001 ; \mathrm{GSI} \mathrm{M}=0.15, \mathrm{SD}=0.1$ vs. $\mathrm{M}=0.28, \mathrm{SD}=0.23$; $\mathrm{p}=.000 ;$ PST $\mathrm{M}=7.13, \mathrm{SD}=4.91$ vs. $\mathrm{M}=11.90, \mathrm{SD}=$ $8.10 ; \mathrm{p}=.001)$. No differences in mental health between fathers with ventilated children $\left(f_{\mathrm{v}} n=7\right)$ and with nonventilated children $f_{n v}(n=16)$ were found (Fig. 4b).

\section{Discussion}

In face of the growing number of disease-modifying therapies in the field of neuromuscular disorders the quality of life of patients and their families is of central importance for a decision on life-prolonging procedures, such as mechanical ventilation, and the initiation of these therapies. However, previous studies have stated, that HRQOL of technology-dependent and/or physically disabled children might be significantly underestimated by the caregivers $[8,9]$.

Therefore, we evaluated the quality of life and mental health of families with ventilated and non-ventilated children with neuromuscular diseases. As reported by others [12, 13, 26-29], children with neuromuscular diseases and their parents reported a reduced child's overall quality of life especially regarding the Physical and Psychological Well-Being and Social integration and also in some aspects of their mental health compared to healthy children. Moreover, quality of life of our patients was even lower than in the group of children with other chronic diseases. Although technical equipment, for example portable medical devices and long-lasting batteries, has improved over time, our results might reflect the impact of neuromuscular disorders on managing daily life and the proper integration of physically disabled children in their social environment. Surprisingly and in contrast to our hypothesis, these results were irrespective of the need of mechanical ventilation and confirm that ventilator use per se did not negatively influence health-related quality of life and mental health in our 


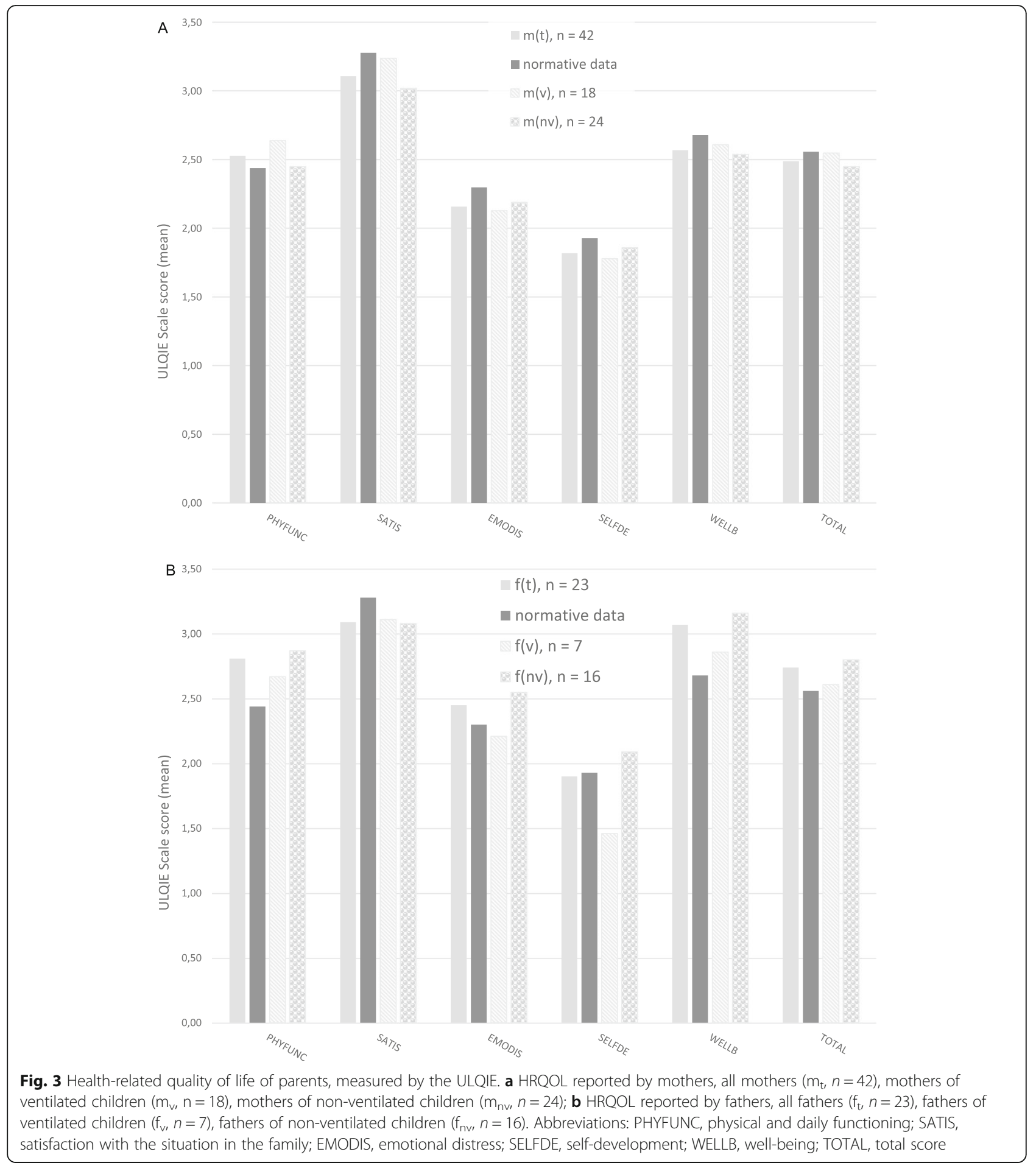

patients. This seems counterintuitive but is consistent with previous reports about the improvement of quality of life after initiation of mechanical ventilation in patients with neuromuscular disease [30, 31]. It also supports our experience in clinical practice with positive effects on physical performance due to mechanical ventilation, mainly in children using non-invasive ventilation in later stages of the disease such as Duchenne muscular dystrophy. Seear et al. (2016) also reported only mild to moderate adverse effects of mechanical ventilation on the quality of life in the majority of home-ventilated children with heterogeneous underlying diseases [13]. Indeed, our results might be influenced by the higher proportion of children with non-invasive ventilation 


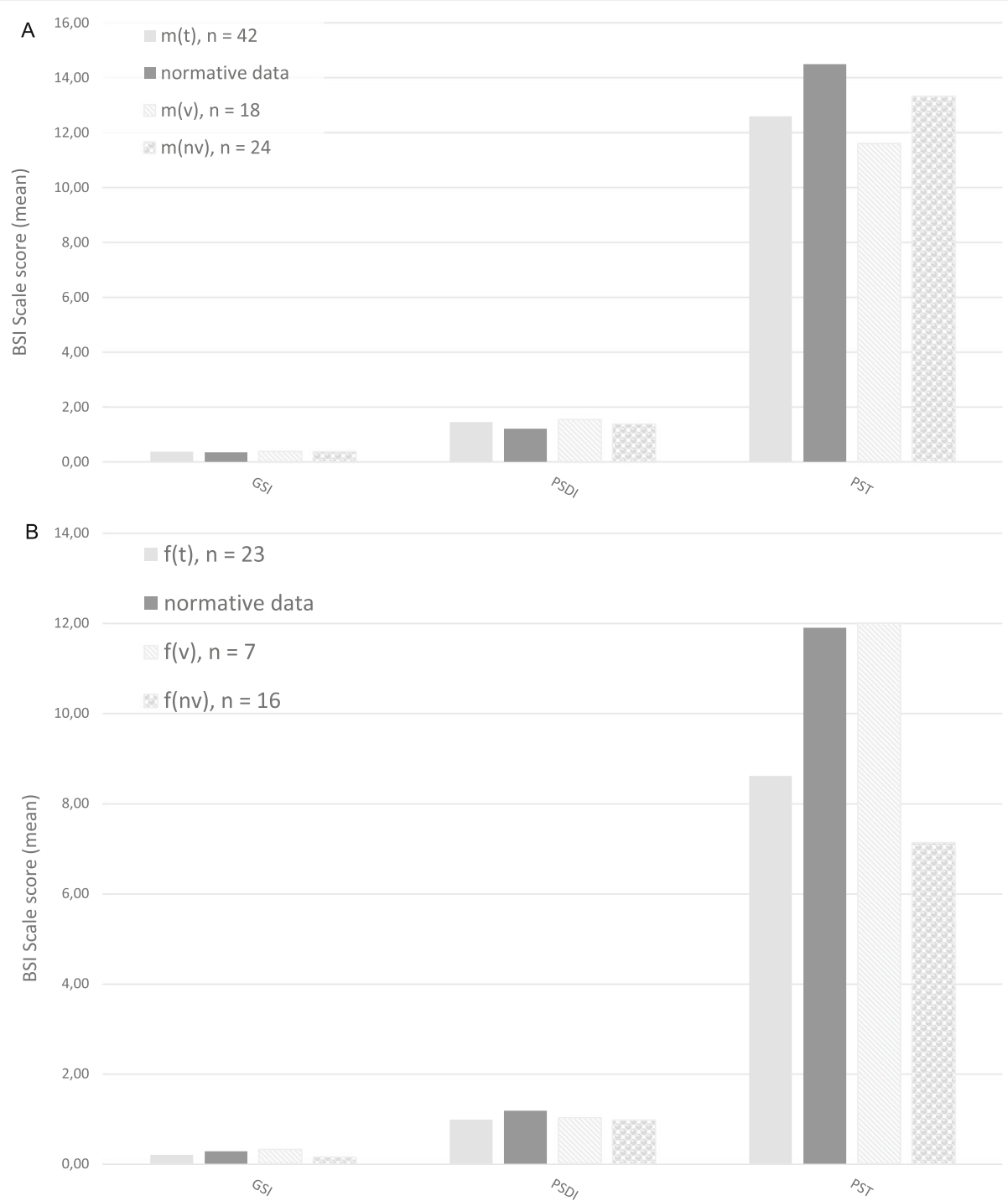

Fig. 4 Mental health of parents, measured by the BSI. a reported by mothers, all mothers $\left(m_{t}, n=42\right)$, mothers of ventilated children $\left(m_{v}, n=18\right)$, mothers of non-ventilated children $\left(m_{n v}, n=24\right)$; $\mathbf{b}$ reported by fathers, all fathers $\left(f_{t}, n=23\right)$, fathers of ventilated children $\left(f_{v}, n=7\right)$, fathers of non-ventilated children $\left(f_{n v}, n=16\right)$. Abbreviations: GSI, Global Severity Index; PSDI, Positive Symptom Distress Index; PST, Positive Symptom Total

(61.1\%) as this might have a lower impact on daily life compared to invasive ventilation. However, some authors associated ventilator use in children with significant lower scores in most aspects of health-related quality of life $[12,16,26]$. These studies included a broader spectrum of underlying medical conditions impairing comparability with our data as the underlying disease itself might contribute to the impairment of quality of life. Mah et al. showed poorer physical and psychosocial HRQOL in Canadian ventilated children compared to non-ventilated children with neuromuscular diseases. Children with home ventilation counted for only $17 \%$ of the study population. Authors interpreted their results as a consequence of disease severity and reduced involvement in social activities of ventilated children [32]. In our population, reduced contact to peers in ventilated children compared to non-ventilated children was reported only by the parents but not by the children themselves. Similar results with fewer relationships with friends were also reported by parents for their home-ventilated children in the study of Noyes et al. (2007) [16]. This might reflect differences in child selfreport and parent proxy measures as indicated by Bray (2017) [9]. HRQOL and mental health outcomes of parents in our population were only to some extent decreased. These results were again not dependent on the use of mechanical ventilation in their children. In fact, in many domains the parents and here especially the fathers scored higher than the normative groups. Though, we realized high scores in the Positive Symptom Distress 
Index that might point towards the tendency to give positive self-descriptions as decribed by Paulhus (2002) [33]. Another explanation might be offered by the Theory of social comparison established by Festinger (1954) [34]. The theory states, that individuals assess their own situation and abilities in relation to others. Assuming that families with chronically ill children are more often in hospital and in contact with families in similar circumstances, their own distress might be modified. Moreover, influencing factors as social support, family dynamics and relations might influence our results but have not been evaluated separately.

Although our study has some limitations due to the small sample size and the heterogenous group of patients regarding the underlying neuromuscular diseases and the kind and duration of mechanical ventilation it should be considered as assisting data, that might influence the perspective on ventilator-use as a life-extending procedure in children with neuromuscular diseases. As the debate about the use of long-term ventilation in severly affected children with neuromuscular disease is still polarizing and often colored by individual experience the results in our patients emphasizes, that ventilator use per se is not the limiting factor for the HRQOL and mental health of affected children and their families.

\section{Conclusions}

Quality of life of patients and families must be a central decision criterium for medical interventions especially in palliative care situations. Therefore, our data contributes an important aspect in the controversial discussion about establishing life-prolonging procedures since ventilator use was not responsible for the reduction of HRQOL and mental health in our population of children with neuromuscular diseases and their families.

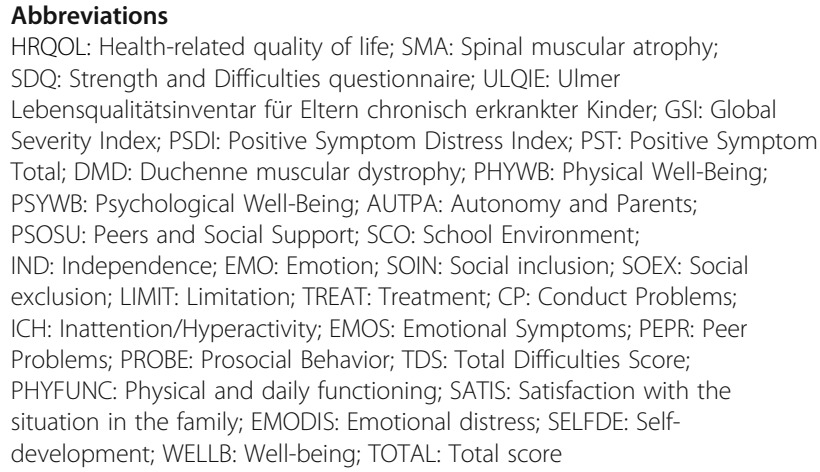

\section{Acknowledgements}

None.

\section{Authors' contributions}

All authors designed the study. JJ, LF and LM collected the data and performed the statistical analysis. JJ drafted the article. All authors interpreted data. SWG and JD revised the manuscript. The author(s) read and approved the final manuscript.

Funding

None.

Availability of data and materials

The datasets used and/or analysed during the current study are available from the corresponding author on reasonable request.

\section{Ethics approval and consent to participate}

All procedures performed in our study involving human participants were in accordance with the ethical standards of the local ethics committee

Hamburg, Germany (PV4361) and with the 1964 Helsinki declaration and its later amendments or comparable ethical standards. Informed consent was obtained from all individual participants included in the study.

\section{Consent for publication \\ Not applicable.}

\section{Competing interests}

The authors declare that they have no competing interests.

\section{Author details}

${ }^{1}$ Department of Pediatrics, University Medical Center Hamburg-Eppendorf, Hamburg, Martinistr, 5220246 Hamburg, Germany. ${ }^{2}$ Children's Hospital Altona, Hamburg, Germany. ${ }^{3}$ Department of child and adolescent psychiatry, psychosomatics and psychotherapy, University Medical Center

Hamburg-Eppendorf, Hamburg, Germany.

Received: 30 May 2019 Accepted: 30 June 2020

Published online: 09 July 2020

\section{References}

1. Bach JR, Saltstein $K$, Sinquee D, Weaver B, Komaroff E. Long-term survival in Werdnig-Hoffmann disease. Am J Phys Med Rehabil. 2007:86(5):339-45.

2. Jeppesen J, Green A, Steffensen BF, Rahbek J. The Duchenne muscular dystrophy population in Denmark, 1977-2001: prevalence, incidence and survival in relation to the introduction of ventilator use. Neuromuscul Disord. 2003;13(10):804-12.

3. Passamano L, Taglia A, Palladino A, Viggiano E, D'Ambrosio P, Scutifero M, et al. Improvement of survival in Duchenne muscular dystrophy: retrospective analysis of 835 patients. Acta Myol. 2012;31(2):121.

4. Finkel RS, Mercuri E, Darras BT, Connolly AM, Kuntz NL, Kirschner J, et al. Nusinersen versus sham control in infantile-onset spinal muscular atrophy. N Engl J Med. 2017;377(18):1723-32.

5. Mercuri E, Darras BT, Chiriboga CA, Day JW, Campbell C, Connolly AM, et al. Nusinersen versus sham control in later-onset spinal muscular atrophy. $\mathrm{N}$ Engl J Med. 2018;378(7):625-35.

6. Hoy SM. Onasemnogene Abeparvovec: First Global Approval. Drugs. 2019; 79:1255-62.

7. Ryan MM, Kilham H, Jacobe S, Tobin B, Isaacs D. Spinal muscular atrophy type 1: is long-term mechanical ventilation ethical? J Paediatr Child Health 2007:43(4):237-42

8. Bray P, Bundy AC, Ryan MM, North KN, Everett A. Health-related quality of life in boys with Duchenne muscular dystrophy: agreement between parents and their sons. J Child Neurol. 2010;25:1188-94.

9. Bray N, Noyes J, Harris N, Edwards RT. Measuring the health-related quality of life of children with impaired mobility: examining correlation and agreement between children and parent proxies. BMC Res Notes. 2017;10: 377.

10. Carnevale FA, Alexander E, Davis M, Rennick J, Troini R. Daily living with distress and enrichment: the moral experience of families with ventilatorassisted children at home. Pediatrics. 2006;117(1):e48-60.

11. Evans R, Catapano M, Brooks D, Goldstein R, Avendano M. Family caregiver perspectives on caring for ventilator-assisted individuals at home. Can Respir J. 2012;19:373-9.

12. González R, Bustinza A, Fernandez SN, García M, Rodriguez S, García-Teresa $M A$, et al. Quality of life in home-ventilated children and their families. Eur J Pediatr. 2017;176:1307-17. 
13. Seear M, Kapur A, Wensley D, Morrison K, Behroozi A. The quality of life of homeventilated children and their primary caregivers plus the associated social and economic burdens: a prospective study. Arch Dis Child. 2016;101:620-7.

14. Toly VB, Musil CM, Carl JC. A longitudinal study of families with technologydependent children. Res Nurs Health. 2012;35:40-54.

15. van Oers H, Haverman L, Limperg P, Dijk-Lokkart E, Maurice-Stam H, Grootenhuis M. Anxiety and depression in mothers and fathers of a chronically ill child. Matern Child Health J. 2014. https://doi.org/10.1007/ s10995-014-1445-8.

16. Noyes J. Comparison of ventilator-dependent child reports of health-related quality of life with parent reports and normative populations. J Adv Nurs. 2007;58(1):1-10.

17. Schmidt S, Petersen C, Mühlan H, Simeoni MC, Debensason D, Thyen U, et al. The DISABKIDS questionnaires: quality of life questionnaires for children with chronic conditions. Lengerich: Pabst science publishers; 2006.

18. Simeoni MC, Schmidt S, Muehlan H, Debensason D, Bullinger M, Disabkids Group. Field testing of a European quality of life instrument for children and adolescents with chronic conditions: the 37-item DISABKIDS chronic generic module. Qual Life Res. 2007;16:881-93.

19. Sandeberg af M, Johansson EM, Hagell P, Wettergren L. Psychometric properties of the DISABKIDS Chronic Generic Module (DCGM-37) when used in children undergoing treatment for cancer. Health Qual of Life Outcomes. 2010;8:109.

20. Ravens-Sieberer U, Auquier P, Erhart M, Gosch A, Rajmil L, Bruil J, et al. The KIDSCREEN-27 quality of life measure for children and adolescents: psychometric results from a cross-cultural survey in 13 European countries. Qual Life Res. 2007;16(8):1347-56.

21. Goodman R. The strengths and difficulties questionnaire: a research note. J Child Psychol Psychiatry. 1997;38(5):581-6.

22. Hölling H, Schlack R, Petermann F, Ravens-Sieberer U, Mauz E, KiGGS Study Group. Psychische Auffälligkeiten und psychosoziale Beeinträchtigungen bei Kindern und Jugendlichen im Alter von 3 bis 17 Jahren in DeutschlandPrävalenz und zeitliche Trends zu 2 Erhebungszeitpunkten (2003-2006 und 2009-2012). Bundesgesundheitsblatt-GesundheitsforschungGesundheitsschutz. 2014:57(7):807-19.

23. Goldbeck L, Storck M. Das Ulmer Lebensqualitäts-Inventar für Eltern chronisch kranker Kinder (ULQIE). Z Klin Psychol Psychother. 2002;31(1):31-9.

24. Derogatis $L R$, Melisaratos $N$. The brief symptom inventory: an introductory report. Psychol Med. 1983;13(3):595-605.

25. Franke HG. BSI: Brief symptom inventory from Derogatis (short form of SCL90-R), German version, manual: Beltz test. 2000.

26. Baiardini I, Minetti C, Bonifacino S, Porcu A, Klersy C, Petralia P, et al. Quality of life in Duchenne muscular dystrophy: the subjective impact on children and parents. J Child Neurol. 2011;26(6):707-13.

27. Landfeldt E, Lindgren P, Bell CF, Guglieri M, Straub V, Lochmüller H, Bushby K. Health-related quality of life in patients with Duchenne muscular dystrophy: a multinational, cross-sectional study. Dev Med Child Neurol. 2016;58(5):508-15.

28. Uzark K, King E, Cripe L, Spicer R, Sage J, Kinnett K, et al. Health-related quality of life in children and adolescents with Duchenne muscular dystrophy. Pediatrics. 2012. https://doi.org/10.1542/peds.2012-0858.

29. Wei Y, Speechley KN, Zou G, Campbell C. Factors associated with healthrelated quality of life in children with Duchenne muscular dystrophy. J Child Neurol. 2016;31(7):879-86.

30. Kohler M, Clarenbach CF, Böni L, Brack T, Russi EW, Bloch KE. Quality of life, physical disability, and respiratory impairment in Duchenne muscular dystrophy. Am J Respir Crit Care Med. 2005;172(8):1032-6.

31. Vuillerot C, Hodgkinson I, Bissery A, Schott-Pethelaz AM, Iwaz J, Ecochard R, et al. Self-perception of quality of life by adolescents with neuromuscular diseases. J Adolesc Health. 2010;46(1):70-6.

32. Mah JK, Thannhauser JE, Kolski H, Dewey D. Parental stress and quality of life in children with neuromuscular disease. Pediatr Neurol. 2008:39:102-7.

33. Paulhus DL. Socially desirable responding: the evolution of a construct. In Braun HI, Jackson DN, Wiley DE, editors. The role of contructs in psychological and educational measurement. Mahwah NY: Erlbaum; 2002.

34. Festinger L. A theory of social comparison processes. Hum Relat. 1954;7(2): $117-40$

\section{Publisher's Note}

Springer Nature remains neutral with regard to jurisdictional claims in published maps and institutional affiliations.

\section{Ready to submit your research? Choose BMC and benefit from}

- fast, convenient online submission

- thorough peer review by experienced researchers in your field

- rapid publication on acceptance

- support for research data, including large and complex data types

- gold Open Access which fosters wider collaboration and increased citations

- maximum visibility for your research: over $100 \mathrm{M}$ website views per year

At BMC, research is always in progress.

Learn more biomedcentral.com/submissions 